\title{
Effect of different factors on patient perception of surgical discomfort in third molar surgery
}

\author{
Giselle Emilãine da Silva REIS(a) \\ Robson Diego CALIXTO(a) iD \\ Maria Fernanda Pivetta \\ PETINATI(b) iD \\ Juliana Feltrin de SOUZA(a) iD \\ Erika Calvano KUCHLER(b) \\ Delson João da $\operatorname{COSTA}^{(a)}$ iD \\ Daniel BONOTTO(c) iD \\ Nelson Luis Barbosa \\ REBELLATO(a) $^{(i D}$ \\ Rafaela SCARIOT(a) \\ (a) Universidade Federal do Paraná - UFPR, \\ Department of Stomatology, Curitiba, \\ PR, Brazil \\ (b) Universidade Positivo - UP, Department of \\ Dentistry, Curitiba, PR, Brazil, \\ (c) Universidade Federal do Paraná - UFPR, \\ Department of Restorative Dentistry, \\ Curitiba, PR, Brazil.
}

Declaration of Interests: The authors certify that they have no commercial or associative interest that represents a conflict of interest in connection with the manuscript.

\section{Corresponding Author:}

Rafaela Scariot

E-mail: Rafaela_scariot@yahoo.com.br

https://doi.org/10.1590/1807-3107bor-2021.vol35.0007

Submitted: March 12, 2020

Accepted for publication: June 6, 2020

Last revision: August 19, 2020
Abstract: The aim of this study was to evaluate patient perception of surgical discomfort in third molar surgery and the association with clinical variables and polymorphisms associated with the FKBP5, SLC6A4, and COMT genes. This cross-sectional observational study was carried out on 196 participants aged between 18 and 64 years at the Federal University of Paraná in 11 months. The intensity of surgical discomfort was assessed using the QCirDental questionnaire. Data on surgical and individual procedures were also cataloged. The oral health related quality of life was assessed by the Oral Health Impact Profile questionnaire (OHIP-14). The DNA sample was obtained from cells of the oral mucosa. Five markers of the FKBP5, SLC6A4, and COMT genes were genotyped. The data were submitted to statistical analysis with a significance level of $5 \%$. Women reported greater intensity of discomfort associated with third molar surgery compared to men $(p=0.001)$. In the recessive model, the AA genotype of the rs3800373 marker was associated with greater surgical discomfort $(p=0.026)$. Therefore, women and individuals of the AA genotype for the rs3800373 marker in the FKBP5 gene reported greater surgical discomfort associated with third molar surgery.

Keywords: Surgery, Oral; Molar, Third; Quality of Life; Polymorphism, Genetic.

\section{Introduction}

Third molar extraction is a common oral surgical procedure performed worldwide. ${ }^{1}$ Some studies have attempted to investigate the clinical and radiographic factors that can predict surgical difficulties or postoperative complications associated with third molar extraction from a professional outlook..$^{2,3,4,5}$ However, the patient's perspective at the time of surgery is poorly explored. ${ }^{6}$ The QCirDental questionnaire ${ }^{7}$ is designed to evaluate the patient's perception of the quality of the oral surgical procedure in the operative and immediate postoperative period. This questionnaire helps evaluate important individual aspects and the patient's response to the quality of the treatment, ${ }^{7}$ so that strategies to decrease anxiety and complications during surgery can be instituted.

The factors that affect the perception of patients scheduled for third molar extraction are not well known. Evidence has shown that women are 
more sensitive to experimental pain stimuli than men. ${ }^{8}$ Further, older patients, ${ }^{3}$ less experienced surgeon, and longer duration of the surgical procedure ${ }^{9}$ are factors associated with a worse perception of the postoperative period. Additionally, surgical flap procedure and anesthesia supplementation ${ }^{7}$ during third molar extraction are associated with a higher degree of surgical discomfort. The quality of life has been investigated postoperatively after third molar surgeries, ${ }^{10}$ however, the oral health-related quality of life seems to be also an important variable associated with individual perceptions.

Recently, some studies associated genetic polymorphism with different perceptions of pain, anxiety, and psychiatric disorders. ${ }^{11,12,13,14}$ The FKBP Prolyl Isomerase 5 (FKBP5) gene was associated with posttraumatic disorders, ${ }^{15}$ major depressive disorders, ${ }^{16}$ and anxiety. ${ }^{17}$ Solute Carrier Family 6 member 4 (SLC6A4) gene and Catechol-O-methyltransferase (COMT) gene were previously associated with painful conditions and anxiety disorders. ${ }^{11,12,13,14}$ These genes could be responsible for individual variation in the perception of the surgical procedure of third molar extraction.

In the present study, we hypothesized that the surgical discomfort of the patient is influenced by several factors including genetic factors. The knowledge of such factors will enable the provision of personalized treatment in dental practice. Therefore, this study aimed to investigate the effect of clinical aspects and individual genetic background on surgical discomfort in third molar extraction.

\section{Methodology}

\section{Study design and sample}

This observational cross-sectional study was evaluated and approved by the local ethics committee (\# 73771917.5.0000.0102) and was performed in accordance with the principles of the Helsinki Declaration and theSTREGA guidelines for conducting observational studies. ${ }^{18}$ The study was conducted from February to December 2018. The sample comprised 196 patients from the Oral and Maxillofacial Surgery Department scheduled for third molar extraction surgery who accepted to participate in this research.
Inclusion criteria were participants older than 18 years and indicated for surgical extraction of the third molars. Exclusion criteria were patients who had taken anxiolytic medications prior to the surgical procedure, patients with systemic diseases (American Society of Anesthesiologists Classification ASA I and ASA II), and patients with intellectual disabilities not able to answer the questionnaire properly.

It is important to emphasize that in the Surgery Department, the patients that present infection and/or inflammation are not submitted to the procedure. Besides, there is not a medication protocol to control anxiety or decrease the signs of inflammation preoperatively. Therefore, the participants did not use any medication prior to the surgery.

The sample size was calculated considering the following parameters: an estimated population of 500 individuals who undergo third molars extractions in a year at the University, an anticipated frequency of $50 \%$, a confidence limit of $5 \%$, and a design effect of 1 . Using these parameters, the calculations resulted in a sample size of 218 individuals (www.openepi.com/samplesize).

Briefly, patients seeking third molar surgery at the University were invited to participate in the study. The patients that agreed to participate in the research were evaluated in a separate room. The personal data were collected and then the participant answered the OHIP-14 questionnaire. Subsequently, a mouthwash with a 3\% glucose solution was performed for two minutes, and cheek cells were collected with oral swabs for DNA extraction. The $15-\mathrm{mL}$ conical centrifuge tubes from each patient containing the genetic sample were stored at $-20^{\circ} \mathrm{C}$. The patient was then referred to the Surgical Room for third molar surgery, during which the examiner collected surgical data. At the end of the surgery, after the post-operative orientations, the patient answered the QCirdental questionnaire in a separate room.

\section{Individual and surgical data evaluated}

Individual characteristics such as sex (female or male), age, and body mass index (BMI, calculated by dividing weight (in kilograms) by height (in meters) squared) were recorded. Based on the recommendations of the World Health Organization 
(WHO), participants were classified as underweight, normal weight, overweight, and obese.$^{19}$ The surgical variables were as follows: operating dentist residency stage (R1, R2, or R3 - categorized according to the year (of a total of 3 years) of training in Oral and Maxillofacial Residency Program); surgery duration (in minutes from the arrival in the operating room until the end of the surgical procedure); and the number of teeth removed ( $\leq 2$ or $\geq 3$, as in some situations, the four third molars were not removed in the same procedure, but in two periods, two teeth per period).

The difficulty level of disimpaction of the third molars was determined using panoramic radiographs by a single researcher (GESR) previously trained by a senior researcher (RS). The Winter's classification ${ }^{20}$ was used to determine the long axis angulation of the impacted third molar relative to the long axis of the adjacent second molar, classifying the third molar as having mesioangular, vertical, horizontal, and distoangular impactions. The Pell \& Gregory's classification ${ }^{21}$ was used to evaluate the relationship of the third molar with the anterior border of the mandibular ramus, which was classified in class I, II, or III. This also classifies the relationship of the third molar with the occlusal plane, that is, the depth of the impacted tooth compared to the occlusal plane of the adjacent second molar, which was classified as class A, B, or C. Patients in whom more than one third molar was removed were considered with the highest difficulty of extraction.

\section{OHIP-14 questionnaire}

The oral health-related quality of life was evaluated through the OHIP-14 questionnaire, ${ }^{22}$ using a version validated for the Brazilian Portuguese language. ${ }^{23}$ The data were collected before the surgical procedure and immediately after. The questionnaire consists of 14 questions grouped into seven domains that measure functional limitation (D1), physical disability (D2), psychological discomfort (D3), physical incapacity (D4), psychological disability (D5), social disability (D6), and social disadvantage (D7). The response scale is: 0 - never, 1 - rarely, 2 - sometimes, 3 - often, and 4 - always. The higher the value attributed by the respondent, the worse the self-perceived effect.

\section{Surgical technique}

The surgical procedure was performed by first, second, or third-year residents under local anesthesia with 3\% mepivacaine and 1:100000 norepinephrine for all included subjects. The surgical wound was approximated by 4-0 nylon sutures in all cases.

\section{QCirDental questionnaire}

QCirDental is a questionnaire developed and validated for the Brazilian Portuguese language to quantify the negative impact and discomfort associated with the surgical procedure. ${ }^{7}$ Immediately after the surgery, participants completed the questionnaire in a separate room with the presence of the researcher only, who was previously trained to use the QCirDental questionnaire. The questionnaire consists of 20 items about the discomfort during the operative and the immediate postoperative periods answered on a scale from 0 (no discomfort) to 10 (highest level of discomfort). The degree of the effect (represented in this study as intensity of discomfort) is the sum of the scores of individual questions divided by the number of questions.

\section{Genetic analysis}

The patients' DNA samples were collected from the buccal mucosa cells through a 2-minute mouthwash with isotonic $3 \%$ glucose solution. ${ }^{24}$ The investigator also scrapped the buccal mucosa using a sterilized wooden spatula. The sample was purified with $10 \mathrm{mM}$ ammonium acetate and $1 \mathrm{mM}$ ethylenediamine tetraacetic acid (EDTA). ${ }^{25}$

Five polymorphisms of the FKBP5, SLC6A4, and COMT genes were genotyped by the real-time polymerase chain reaction (PCR) technique using the StepOnePlus ${ }^{\mathrm{TM}}$ Real-Time PCR System (Thermo Fisher Scientific, Foster City, USA). All the polymorphisms used in this study were chosen if their minimum allele frequency was greater than $30 \%$. The genetic polymorphism $r s 3800373(\mathrm{G}>\mathrm{T})$ and $r s 1360780(\mathrm{~A}>\mathrm{C})$ in FKBP5 were chosen because of previous associations with borderline personality disorder, ${ }^{26}$ post-traumatic stress disorder, ${ }^{15}$ depressive disorder ${ }^{16}$ and anxiety. ${ }^{17}$ The genetic polymorphisms rs1042173 (A > C) and rs3813034 (A > C) in SLC6A4, and rs174675 in COMT were selected due to their previous associations with 
pain conditions and anxiety. ${ }^{11,12,13,14}$ Table 1 summarizes the genetic polymorphisms selected for the study.

\section{Statistical analysis}

Data were analyzed using the Statistical Package for the Social Science (IBM SPSS for Apple OS, version 21.0, IBM Corp. Armonk, USA). The dependent variable was QCirDental scores, and the scores were compared between the categories of the independent variables sex, age, and BMI, variables inherent to the surgical procedure of third molar extraction, quality of life, and genetic variables. The QCirDental scores presented non-normal distribution according to the Kolmogorov-Smirnov test, and hence, the data were represented by median, minimum, and maximum. The difference between the QCirDental scores and the independent variables were analyzed using the Mann-Whitney U Test or the Kruskal-Wallis test (in more than two groups). All inferential analyses were attributed a level of significance of $p<0.05$. The variable age ( $\geq 23$ or $<23$ years) and the variable duration of surgery ( $\geq 50$ minutes or $<50$ minutes) were dichotomized by their respective medians, since they were distributed non-parametrically. The correlation between QCirDental and OHIP-14 scores was determined using the Spearman's correlation coefficient. Genotype distributions were evaluated in additive, dominant, and recessive models for the FKBP5 and SLC6A4 genes, while for the COMT gene, only the additive model was evaluated as none of the patients had a TT genotype. The Hardy-Weinberg equilibrium was evaluated by the Chi-square test.

\section{Results}

Initially, two hundred and nine participants were selected for the study. During the recruitment, 13 individuals were excluded: eight were absent at the time of anamnesis or DNA collection and five did not give consent for the procedure. Therefore, the final sample consisted of 196 participants, and 428 extracted third molars (Figure). Of these, 59.7\% $(n=117)$ were women and $40.3 \%(n=79)$ were men. The median age was 23 years (ranging from: 18-64), and the median BMI was 23.40 (ranging from: 16.3-34.7).

The prevalence of discomfort as quantified by the QCirDental questionnaire was $81 \%$. The median score was 1.40 (ranging from 0-6). The association between QCirDental scores and demographic variables is presented in Table 2. Women reported greater intensities of discomfort associated with third molar surgeries compared to men $(\mathrm{p}=0.001)$. There was no significant association between the variables age and body mass index (BMI) with intensity of surgical discomfort $(p>0.05)$.

Table 3 describes the surgical variables associated with discomfort. There was no significant association of surgeon experience, duration of surgery, number of teeth extracted, Winter's classification, and Pell and Gregory's classification with greater intensity of discomfort in third molar surgeries ( $p>0.05$ ).

Table 4 describes the correlation between OHIP-14 and perception of surgical discomfort. Besides the general score, the domains of physical limitation, physical disability, psychological

Table 1. Characteristics of the studied genetic polymorphisms.

\begin{tabular}{|c|c|c|c|c|}
\hline Gene & Polymorphisms & Locus & Change of base & Minor allele frequency/number of individuals assessed* \\
\hline \multirow{4}{*}{ FKBP5 } & \multirow{2}{*}{ rs3800373 } & & \multirow{2}{*}{ C/A } & $C=0.32867$ \\
\hline & & $6 p .21 .31$ & & $A=0.67133$ \\
\hline & \multirow{2}{*}{ rs1360780 } & & \multirow{2}{*}{$\mathrm{T} / \mathrm{C}$} & $\mathrm{T}=0.33611$ \\
\hline & & & & $C=0.66389$ \\
\hline \multirow{4}{*}{ SLC6A4 } & \multirow{2}{*}{ rs 1042173} & & \multirow{2}{*}{$\mathrm{A} / \mathrm{C}$} & $C=0.41885$ \\
\hline & & $17 q 11.2$ & & $A=0.58115$ \\
\hline & \multirow{2}{*}{ rs3813034 } & & \multirow{2}{*}{$\mathrm{A} / \mathrm{C}$} & $C=0.32867$ \\
\hline & & & & $A=0.67133$ \\
\hline \multirow{2}{*}{ COMT } & \multirow{2}{*}{ rs 174675} & \multirow{2}{*}{$22 q 11.21$} & \multirow{2}{*}{$\mathrm{T} / \mathrm{C}$} & $T=0.32890$ \\
\hline & & & & $C=0.67110$ \\
\hline
\end{tabular}

Source of information: dbSNP at https://www.ncbi.nlh.nih.gov/snp/; http://genome.uscs.edu/. 


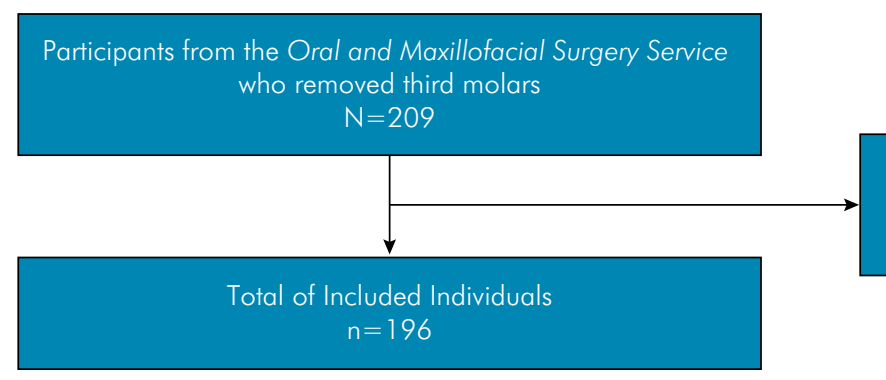

Participants excluded (n-13) due to:

- Not showing at data or DNA collection moment $(n=8)$

- Not urdergo surgery to remove the third molar $(n=5)$

Figure. Flow chart illustrating stages of the study.

Table 2. Median (min and max) scores for surgical discomfort according to individual characteristics of the sample.

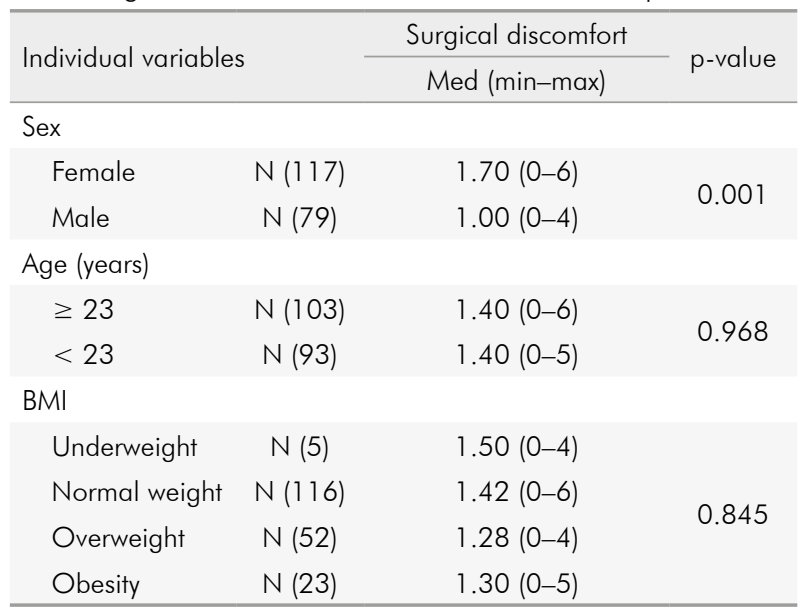

*Mann-Whitney $U$ test with significance level of 0.05 . Bold values indicate statistical significance. Med: median; Min: minimum; Max: maximum; BMI: Body mass index.

discomfort, psychological disability, social disability, and social disadvantage were considered separately, and no correlation was found between higher scores and greater perception of discomfort in third molar surgeries $(p>0.05)$.

Table 5 shows the association between surgical discomfort and genetic polymorphisms in FKBP5, SLC6A4, and COMT. The genotypic frequencies of the polymorphisms were in Hardy-Weinberg equilibrium (data not shown). No statistically significant differences were evident for the genetic polymorphisms rs1360780, rs1042173, rs3813034, and rs174675 ( $\mathrm{p}>0.05$ ). For the genetic polymorphism rs3800373 in FKBP5, in the recessive model, individuals with AA genotype reported greater surgical discomfort with third molar surgery compared to individuals with CC/AC genotypes $(p=0.026)$.

\section{Discussion}

The outcomes of third molar surgery that have been studied thoroughly include postoperative complications ${ }^{9}$ such as the presence of pain, ${ }^{27,28}$ occurrence of trismus, and swelling in the postoperative period. ${ }^{26}$ However, patient-centered outcomes as well as individual factors associated with patient's perception regarding treatment in the operative or immediate postoperative period are poorly explored in dentistry.

To the best of our knowledge, this is the first study performed using the QCirDental questionnaire other than its validation study. ${ }^{7}$ In the original study, the mean surgical discomfort was 0.7. The mean for our sample was higher. However, contrary to our study, the original study used the questionnaire in patients who underwent any dental surgery excluding third molar surgery. ${ }^{7}$ It is noteworthy that although most individuals reported low discomfort during the surgical procedure, only $19 \%$ individuals reported no discomfort.

Among the individual variables, only female sex was significantly associated with higher intensity of surgical discomfort. A study conducted by Fillingim et al. ${ }^{12}$ in 2009 showed that substantial gender differences exist in clinical and experimental responses to pain, ${ }^{12}$ and females report higher pain perception. The current literature shows that women are at higher risk for chronic pain and may experience more severe clinical pain. ${ }^{29}$ Women in the reproductive age appear to be more susceptible to chronic pain. ${ }^{30}$ It is worth noting that our study included mostly women in the reproductive age.

Studies about the effect of the menstrual cycle on the threshold of pain perception are conflicting. ${ }^{31,32,33,34}$ 
Effect of different factors on patient perception of surgical discomfort in third molar surgery

Table 3. Median (min and max) scores for surgical discomfort according to surgical variables.

\begin{tabular}{|c|c|c|c|c|}
\hline \multirow{2}{*}{ Surgical variables } & & & Surgical discomfort & \multirow{2}{*}{$\mathrm{p}$-value } \\
\hline & & & Med (min-max) & \\
\hline \multirow{3}{*}{ Resident's training stage } & $\mathrm{R} 1$ & $N(56)$ & $1.42(0-5)$ & \multirow{3}{*}{0.479} \\
\hline & R2 & $N(69)$ & $1.33(0-4)$ & \\
\hline & R3 & $N(60)$ & $1.55(0-6)$ & \\
\hline \multirow{2}{*}{ Surgery duration (minutes) } & $\geq 50$ & $N(90$ & $1.15(0-6)$ & \multirow{2}{*}{0.136} \\
\hline & $<50$ & $N(106)$ & $1.58(0-5)$ & \\
\hline \multirow{2}{*}{ Number of teeth extracted } & $\geq 2$ & $N(156)$ & $1.40(0-6)$ & \multirow{2}{*}{0.882} \\
\hline & $\leq 3$ & N (38) & $1.40(0-4)$ & \\
\hline \multicolumn{5}{|l|}{ Winter's classification } \\
\hline \multirow{3}{*}{ Teeth 18} & Distoangulated & $\mathrm{N}(25)$ & $1.45(0-3)$ & \multirow{3}{*}{0.997} \\
\hline & Mesioangulated & $N(7)$ & $1.20(0-5)$ & \\
\hline & Vertical & $N(81)$ & $1.58(0-4)$ & \\
\hline \multirow{3}{*}{ Teeth 28} & Distoangulated & $N(15)$ & $1.45(0-3)$ & \multirow{3}{*}{0.059} \\
\hline & Mesioangulated & $N(10)$ & $0.75(0-2)$ & \\
\hline & Vertical & $N(63)$ & $1.40(0-6)$ & \\
\hline \multirow{5}{*}{ Teeth 38} & Distoangulated & $N(9)$ & $1.10(0-2)$ & \multirow{5}{*}{0.839} \\
\hline & Mesioangulated & $N(24)$ & $1.65(0-3)$ & \\
\hline & Vertical & N (45) & $1.48(0-6)$ & \\
\hline & Horizontal & $N(17)$ & $1.20(0-3)$ & \\
\hline & Transalveolar & $N(1)$ & - & \\
\hline \multirow{5}{*}{ Teeth 48} & Distoangulated & $N(11)$ & $2.15(0-5)$ & \multirow{5}{*}{0.587} \\
\hline & Mesioangulated & N (33) & $1.98(0-4)$ & \\
\hline & Vertical & $N(54)$ & $1.38(0-5)$ & \\
\hline & Horizontal & N (19) & $1.15(0-3)$ & \\
\hline & Transalveolar & $N(2)$ & $0.92(1-1)$ & \\
\hline \multicolumn{5}{|l|}{ Pell \& Gregory Classification } \\
\hline \multirow{3}{*}{ Teeth 18} & A & $N(60)$ & $1.70(0-4)$ & \multirow{3}{*}{0.308} \\
\hline & $\mathrm{B}$ & $N(23)$ & $1.45(0-4)$ & \\
\hline & C & N (29) & $1.50(0-5)$ & \\
\hline & $A$ & $N(46)$ & $1.05(0-6)$ & \\
\hline Teeth 28 & $\mathrm{~B}$ & $N(15)$ & $1.60(0-4)$ & 0.126 \\
\hline & C & $N(27)$ & $1.50(0-4)$ & \\
\hline & IA & $N(36)$ & $1.70(0-6)$ & \\
\hline & IB & $N(15)$ & $1.40(0-3)$ & \\
\hline & IC & $N(3)$ & $1.28(1-1)$ & \\
\hline Teeth 38 & $\| \mathrm{A}$ & $N(20)$ & $1.40(0-3)$ & 0.216 \\
\hline & $\| B$ & $N(13)$ & $1.78(0-3)$ & \\
\hline & $\| C$ & $N(6)$ & $0.80(0-1)$ & \\
\hline & IIIB & N (3) & $1.15(0-2)$ & \\
\hline & $\mid A$ & $N(34)$ & $1.48(0-4)$ & \\
\hline & IB & $N(19)$ & $1.30(2-3)$ & \\
\hline & IC & $N(4)$ & $2.05(2-3)$ & \\
\hline & $\| A$ & $N(26)$ & $1.42(0-5)$ & 0803 \\
\hline leeth 48 & IIB & $N(27)$ & $1.40(0-5)$ & 0.803 \\
\hline & $\| \mathrm{C}$ & $N(6)$ & $1.95(0-3)$ & \\
\hline & IIIA & $N(1)$ & - & \\
\hline & $\| \mathrm{IIB}$ & $N(3)$ & $1.95(1-2)$ & \\
\hline & Easy & $N(7)$ & $1,90(1-3)$ & \\
\hline Difficulty level & Medium & N (85) & $1,50(0-6)$ & 0.469 \\
\hline & Difficult & $N(98)$ & $1,45(0-5)$ & \\
\hline
\end{tabular}

*Kruskal-Wallis and Mann-Whitney $U$ test with significance level of 0.05 . 
Table 4. Correlation between OHIP-14 and perception of surgical discomfort.

\begin{tabular}{lcc}
\hline OHIP-14 & $\begin{array}{c}\text { Spearman correlation } \\
\text { coefficient }\end{array}$ & p-value \\
\hline Functional Limitation & 0.087 & 0.238 \\
Physical disability & 0.045 & 0.546 \\
Psychological discomfort & 0.076 & 0.302 \\
Physical incapacity & 0.052 & 0.480 \\
Psychological disability & 0.039 & 0.596 \\
Social disability & 0.113 & 0.126 \\
Social disadvantage & -0.014 & 0.849 \\
OHIP-14 general & 0.093 & 0.210 \\
\hline *Spearma
\end{tabular}

*Spearman's Correlation Coefficient, with significance level of 0.05 .

Different studies showed that the perception of pain in the luteal phase is higher. ${ }^{31,32}$ However, others found no association between the menstrual cycle phase and the painful response. ${ }^{33,34}$ In addition, research relating the response to chronic and acute pain with phases of the menstrual cycle is scarce. ${ }^{31}$ Although our study did not investigate this variable, we strongly encourage future studies to investigate the relationship between phase of menstrual cycle and surgical discomfort.

Although there is no association between age and surgical discomfort, three studies have shown that age is a critical individual factor associated with surgical difficulty, ${ }^{3,4,9}$ a variable that this study did not analyze. However, we hypothesized that the difficulty of surgery could be related to the perception of surgical discomfort. We believe that the lack of association with age might be due to the characteristic of our service of attending young adults; ${ }^{35}$ as observed, the median age of our sample was 23 years and only $12.76 \%$ of the sample was older than 30 years.

The association between BMI and surgical discomfort was evaluated because we raised the hypothesis that overweight and obese patients could report a greater perception of surgical discomfort. Although we found no association between these variables, previous evidence suggests that higher BMI was associated with adverse effects during trans-operative third molar removal and that overweight and obese patients are highly prone to experiencing morbidities. ${ }^{36}$

In the conception of this study, it was hypothesized that variables related to the surgical procedure could affect the patient's perception of the procedure. Therefore, it was determined that the year of residency of the dentist, duration of surgery, number of teeth removed, and radiographic classification of the teeth should be evaluated. However, our study did not find an association between surgical discomfort and the experience of the surgeon who performed the extraction. Akadiri et al. ${ }^{37}$ systematically reviewed a series of seven studies on the principal variables affecting surgical difficulties reported by dental surgeons and showed that the surgeon's experience is important in the level of surgical difficulty. The reason for not finding an association in our study might be related to all residents enrolled in the study having sufficient experience in third molar surgery. Regarding the number of teeth extracted, the majority of patients underwent extractions of two or more third molars, not allowing a conclusion of whether individuals who underwent more extractions in the same appointment experienced more surgical discomfort. Furthermore, the duration of the surgical procedure was not associated with surgical discomfort, despite the consensus in the literature that surgical time seems to be an adequate measure to evaluate surgical difficulty. $3,4,5,9$

In this study, all the extracted third molars were classified using panoramic radiographs according to the classification by Winter and Pell \& Gregory. We found no association between radiographic classification of technical difficulty and surgical discomfort. This result agrees with the conclusion of recent studies that have questioned the efficacy of the Pell \& Gregory's classification in predicting the difficulty of the surgery in some situations.,37 Alvira-González et al. found the classes A, B, and $C$ of the Pell and Gregory's classification ineffective in determining surgical difficulty. ${ }^{5}$ Garcia et al. ${ }^{38}$ conducted a study to determine the specificity and sensitivity of the Pell \& Gregory's classification in predicting the surgical difficulties in third molar surgery and concluded that it is not a reliable predictor of surgical difficulty in the extraction of vertically impacted mandibular third molars. In addition, the authors demonstrated that several surgeries of class II and class III teeth were found to be relatively easy and radiographs alone could not predict the 
Effect of different factors on patient perception of surgical discomfort in third molar surgery

Table 5. Association between surgical discomfort with third molar extraction and genetic polymorphisms.

\begin{tabular}{|c|c|c|c|c|}
\hline \multirow{2}{*}{ Gene } & \multirow{2}{*}{ Polymorphisms } & \multirow{2}{*}{ Model } & Surgical discomfort & \multirow{2}{*}{ p-value } \\
\hline & & & Med (min-max) & \\
\hline \multirow{20}{*}{ FKBP5 } & \multirow{10}{*}{ rs 7360780} & Additive & & \multirow{4}{*}{0.408} \\
\hline & & $\mathrm{CC}$ & $1.20(0-5)$ & \\
\hline & & $\mathrm{TT}$ & $2.23(0-5)$ & \\
\hline & & СТ & $1.75(0-4)$ & \\
\hline & & Dominant & & \multirow{3}{*}{0.302} \\
\hline & & $\mathrm{CC} / \mathrm{CT}$ & $1.45(0-5)$ & \\
\hline & & $\mathrm{TT}$ & $2.23(0-5)$ & \\
\hline & & Recessive & & \multirow{3}{*}{0.274} \\
\hline & & $\mathrm{TT} / \mathrm{CT}$ & $1.20(0-5)$ & \\
\hline & & $\mathrm{CC}$ & $1.80(0-5)$ & \\
\hline & \multirow{10}{*}{ rs3800373 } & Additive & & \multirow{4}{*}{0.074} \\
\hline & & AA & $1.15(0-5)$ & \\
\hline & & $\mathrm{CC}$ & $1.15(0-4)$ & \\
\hline & & $A C$ & $1.90(0-5)$ & \\
\hline & & Dominant & & \multirow{3}{*}{0.921} \\
\hline & & $\mathrm{AA} / \mathrm{AC}$ & $1.45(0-5)$ & \\
\hline & & $\mathrm{CC}$ & $1.15(0-4)$ & \\
\hline & & Recessive & & \multirow{3}{*}{0.026} \\
\hline & & $\mathrm{CC} / \mathrm{AC}$ & $1.15(0-5)$ & \\
\hline & & AA & $1.90(0-5)$ & \\
\hline \multirow{20}{*}{ SLC6A4 } & \multirow{10}{*}{ rs1042173 } & Additive & & \multirow{4}{*}{0.995} \\
\hline & & $\mathrm{AA}$ & $1.15(0-4)$ & \\
\hline & & $\mathrm{CC}$ & $1.30(0-5)$ & \\
\hline & & $A C$ & $1.58(0-5)$ & \\
\hline & & Dominant & & \multirow{3}{*}{0.952} \\
\hline & & $\mathrm{AA} / \mathrm{AC}$ & $1.50(0-5)$ & \\
\hline & & $\mathrm{CC}$ & $1.30(0-5)$ & \\
\hline & & Recessive & & \multirow{3}{*}{0.928} \\
\hline & & $\mathrm{CC} / \mathrm{AC}$ & $1.15(0-4)$ & \\
\hline & & $\mathrm{CC}$ & $1.50(0-5)$ & \\
\hline & \multirow{10}{*}{ rs3813034 } & Additive & & \multirow{4}{*}{0.782} \\
\hline & & $\mathrm{AA}$ & $1.45(0-4)$ & \\
\hline & & $\mathrm{CC}$ & $1.20(0-5)$ & \\
\hline & & $A C$ & $1.70(0-5)$ & \\
\hline & & Dominant & & \multirow{3}{*}{0.489} \\
\hline & & $\mathrm{AA} / \mathrm{AC}$ & $1.55(0-5)$ & \\
\hline & & CC & $1.20(0-5)$ & \\
\hline & & Recessive & & \multirow{3}{*}{0.908} \\
\hline & & $\mathrm{CC} / \mathrm{AC}$ & $1.45(0-4)$ & \\
\hline & & $\mathrm{CC}$ & $1.50(0-5)$ & \\
\hline \multirow{4}{*}{ СОMT } & \multirow{4}{*}{ rs 174675} & Additive & & \\
\hline & & $\mathrm{CC}$ & $1.45(0-5)$ & \\
\hline & & CT & $1.50(0-4)$ & 0.468 \\
\hline & & TT & - & \\
\hline
\end{tabular}

*Kruskal-Wallis Test for additive model and Mann-Whitney $U$ test for dominant and recessive models, with significance level of 0.05 . Bold values indicate statistical significance. 
difficulty of the surgery. We have not found reports of a radiographic classification sufficiently efficient to predict the difficulty of third molar surgeries.

Another aspect evaluated in this study was the effect of oral health-related quality of life on surgical discomfort, but no correlation was found. A noteworthy aspect was that the quality of life questionnaire was completed by the participant before the surgery and emergency surgeries are not usually performed in our field. Thus, the extractions were done without the patient having pre-operatory pain, inflammation, or infection that could affect the quality of life, which might explain the lack of correlation between surgical discomfort and quality of life. This result could be related to the specific sample of the study and may not represent what occurs in the population.

Regarding the association between the genetic polymorphism rs3800373 in FKBP5 and surgical discomfort, our results clearly suggest that genetic biomarkers can predict the experience of third molar surgery. In this study, we chose the FKBP5 gene due to its association with response to posttraumatic stress, ${ }^{15}$ anxiety, ${ }^{17}$ and depressive disorder. ${ }^{16}$ In this sense, we hypothesized that the FKBP5 gene could be associated with individual variations in surgical discomfort, which was confirmed by the result obtained in this study. Individuals with the AA genotype reported greater intensity of surgical discomfort compared to individuals with the CC and AC genotype, indicating that AA might be a biomarker for greater surgical discomfort during oral surgeries. We also evaluated the polymorphism rs174675 in COMT and the polymorphisms rs1042173 and rs3813034 in SLC6A4, because they were previously associated with painful conditions and anxiety, ${ }_{1}^{11,12,13,4}$ but no association was found between these polymorphisms and intensity of surgical discomfort. Future studies with other genetic polymorphisms in the same gene and/or different candidate genes should be performed.

Among the limitations of this study, we did not evaluate the oral condition of study participants to establish a relationship with the oral health-related quality of life. Another limitation is that the patient's anxiety was not evaluated. A recent study that assessed the association between anxiety and pain perception during dental implant surgery found that dental anxiety can increase patients' pain perception during oral implant surgery. ${ }^{39}$ The presence of chronic pain or temporomandibular joint dysfunction was also not evaluated, a variable that could affect surgical discomfort.

In conclusion, females and individuals with AA genotype of the $r s 3800373$ polymorphism in the FKBP5 gene reported the greatest surgical discomfort. These results suggest that genetic variants could be related to patient-centered outcomes such as surgical discomfort. Further studies should analyze the relationship between genetic polymorphisms and patient-centered outcomes.

\section{Acknowledgment}

This study was financed in part by the Coordenação de Aperfeiçoamento de Pessoal de Nível Superior Brasil (CAPES) - Finance Code 001.

\section{References}

1. Aidar M, Line SR. A simple and cost-effective protocol for DNA isolation from buccal epithelial cells. Braz Dent J. 2007;18(2):148-52. https://doi.org/10.1590/S0103-64402007000200012

2. Akadiri OA, Obiechina AE. Assessment of difficulty in third molar surgery: a systematic review. J Oral Maxillofac Surg. 2009 Apr;67(4):771-4. https://doi.org/10.1016/j.joms.2008.08.010

3. Amad A, Ramoz N, Peyre H, Thomas P, Gorwood P. FKBP5 gene variants and borderline personality disorder. J Affect Disord. 2019 Apr;248:26-8. https://doi.org/10.1016/i.jad.2019.01.025

4. Barbosa-Rebellato NL, Thomé AC, Costa-Maciel C, Oliveira J, Scariot R. Factors associated with complications of removal of third molars: a transversal study. Med Oral Patol Oral Cir Bucal. 2011 May;16(3):e376-80. https://doi.org/10.4317/medoral.16.e376

5. Bartley EJ, Fillingim RB. Sex differences in pain: a brief review of clinical and experimental findings. Br J Anaesth. 2013 Jul;111(1):52-8. https://doi.org/10.1093/bja/aet127 
6. Bartley EJ, Rhudy JL. Comparing pain sensitivity and the nociceptive flexion reflex threshold across the mid-follicular and late-luteal menstrual phases in healthy women. Clin J Pain. 2013 Feb;29(2):154-61. https://doi.org/10.1097/AJP.0b013e31824c5edb

7. Benediktsdóttir IS, Wenzel A, Petersen JK, Hintze H. Mandibular third molar removal: risk indicators for extended operation time, postoperative pain, and complications. Oral Surg Oral Med Oral Pathol Oral Radiol Endod. 2004 Apr;97(4):438-46. https://doi.org/10.1016/i.tripleo.2003.10.018

8. Bortoluzzi MC, Martins LD, Takahashi A, Ribeiro B, Martins L, Pinto MH. [Discomfort associated with dental extraction surgery and development of a questionnaire (QCirDental). Part I: impacts and internal consistency]. Cien Saude Colet. 2018 Jan;23(1):267-76. Portuguese. https://doi.org/10.1590/1413-81232018231.16882015

9. Camargo IB, Melo AR, Fernandes AV, Cunningham LL Jr, Laureano Filho JR, Van Sickels JE. Decision making in third molar surgery: a survey of Brazilian oral and maxillofacial surgeons. Int Dent J. 2015 Aug;65(4):169-77. https://doi.org/10.1111/idj.12165

10. Carvalho RW, Vasconcelos BCE. Is overweight a risk factor for adverse events during removal of impacted lower third molars? ScientificWorldJournal. 2014;2014:589856. https://doi.org/10.1155/2014/589856

11. Duarte-Rodrigues L, Miranda EF, Souza TO, Paiva HN, Falci SG, Galvão EL. Third molar removal and its impact on quality of life: systematic review and meta-analysis. Qual Life Res. 2018 Oct;27(10):2477-89. https://doi.org/10.1007/s11136-018-1889-1

12. Fillingim RB, King CD, Ribeiro-Dasilva MC, Rahim-Williams B, Riley JL 3rd. Sex, gender, and pain: a review of recent clinical and experimental findings. J Pain. 2009 May;10(5):447-85. https://doi.org/10.1016/i.jpain.2008.12.001

13. Flegal KM, Carroll MD, Kuczmarski RJ, Johnson CL. Overweight and obesity in the United States: prevalence and trends, 1960-1994. Int J Obes Relat Metab Disord. 1998 Jan;22(1):39-47. https://doi.org/10.1038/sj.ijo.0800541

14. García AG, Sampedro FG, Rey JG, Vila PG, Martin MS. Pell-Gregory classification is unreliable as a predictor of difficulty in extracting impacted lower third molars. Br J Oral Maxillofac Surg. 2000 Dec;38(6):585-7. https://doi.org/10.1054/bjom.2000.0535

15. Gbotolorun OM, Arotiba GT, Ladeinde AL. Assessment of factors associated with surgical difficulty in impacted mandibular third molar extraction. J Oral Maxillofac Surg. 2007 Oct;65(10):1977-83. https://doi.org/10.1016/i.joms.2006.11.030

16. Gottschalk MG, Domschke K. Genetics of generalized anxiety disorder and related traits. Dialogues Clin Neurosci. 2017 Jun;19(2):159-68. [cited 2019 Jun 16] Available from: https://www.ncbi.nlm.nih.gov/pmc/articles/PMC5573560/

17. Hassan S, Muere A, Einstein G. Ovarian hormones and chronic pain: a comprehensive review. Pain. 2014 Dec;155(12):2448-60. https://doi.org/10.1016/i.pain.2014.08.027

18. Hawn SE, Sheerin CM, Lind MJ, Hicks TA, Marraccini ME, Bountress K, et al. GxE effects of FKBP5 and traumatic life events on PTSD: A meta-analysis. J Affect Disord. 2019 Jan;243:455-62. https://doi.org/10.1016/i.jad.2018.09.058

19. Hernández-Díaz Y, González-Castro TB, Tovilla-Zárate CA, Juárez-Rojop IE, López-Narváez ML, Pérez-Hernández N, et al. Association between FKBP5 polymorphisms and depressive disorders or suicidal behavior: A systematic review and meta-analysis study. Psychiatry Res. 2019 Jan;271:658-68. https://doi.org/10.1016/i.psychres.2018.12.066

20. Hettema JM, Neale MC, Kendler KS. A review and meta-analysis of the genetic epidemiology of anxiety disorders. Am J Psychiatry. 2001 Oct;158(10):1568-78. https://doi.org/10.1176/appi.ajp.158.10.1568 PMID:11578982

21. Alvira-González J, Figueiredo R, Valmaseda-Castellón E, Quesada-Gómez C, Gay-Escoda C. Predictive factors of difficulty in lower third molar extraction: a prospective cohort study. Med Oral Patol Oral Cir Bucal. 2017 Jan;22(1):e108-14. Available from: http://dx.doi.org/doi:10.4317/medoral.21348

22. Klatzkin RR, Mechlin B, Girdler SS. Menstrual cycle phase does not influence gender differences in experimental pain sensitivity. Eur J Pain. 2010 Jan;14(1):77-82. https://doi.org/10.1016/i.ejpain.2009.01.002

23. Lindstedt F, Berrebi J, Greayer E, Lonsdorf TB, Schalling M, Ingvar M, et al. Conditioned pain modulation is associated with common polymorphisms in the serotonin transporter gene. PLoS One. 2011 Mar;6(3):e18252. https://doi.org/10.1371/journal.pone.0018252

24. Lindstedt F, Lonsdorf TB, Schalling M, Kosek E, Ingvar M. Perception of thermal pain and the thermal grill illusion is associated with polymorphisms in the serotonin transporter gene. PLoS One. 2011 Mar;6(3):e17752. https://doi.org/10.1371/journal.pone.0017752

25. Little J, Higgins JP, loannidis JP, Moher D, Gagnon F, Elm E, et al. STrengthening the REporting of Genetic Association Studies (STREGA): an extension of the STROBE statement. Genet Epidemiol. 2009 Nov;33(7):581-98. https://doi.org/10.1002/gepi.20410

26. Maria A, Malik M, Virang P. Comparison of primary and secondary closure of the surgical wound after removal of impacted mandibular third molars. J Maxillofac Oral Surg. 2012 Sep;11(3):276-83. https://doi.org/10.1007/s12663-011-0287-9

27. Michelotti A, Liguori R, Toriello M, D'Antò V, Vitale D, Castaldo G, et al. Catechol-O-methyltransferase (COMT) gene polymorphisms as risk factor in temporomandibular disorders patients from Southern Italy. Clin J Pain. 2014 Feb;30(2):129-33. https://doi.org/10.1097/AJP.0b013e318287a358

28. Oliveira BH, Nadanovsky P. Psychometric properties of the Brazilian version of the oral health impact profile-short form. Community Dent Oral Epidemiol. 2005 Aug;33(4):307-14. https://doi.org/10.1111/j.1600-0528.2005.00225.x

29. Pell GJ. Impacted mandibular third molars: classification and modified techniques for removal. Dent Dig. 1933;39(9):330-8.

30. Piroli A, Mattei A, Carta G, D'Alfonso A, Palermo P, Marinangeli F, et al. Influence of the Menstrual Cycle Phase on Pain Perception and Analgesic Requirements in Young Women Undergoing Gynecological Laparoscopy. Pain Pract. 2019 Feb;19(2):140-8. https://doi.org/10.1111/papr.12727 
31. Reissmann DR, Semmusch J, Farhan D, Smeets R, Heiland M, Heydecke G. Development and validation of the Burdens in Oral Surgery Questionnaire (BiOS-Q). J Oral Rehabil. 2013 Oct;40(10):780-7. https://doi.org/10.1111/joor.12092

32. Renton T, Smeeton N, McGurk M. Factors predictive of difficulty of mandibular third molar surgery. Br Dent J. 2001 Jun;190(11):607-10. https://doi.org/10.1038/sj.bdj.4801052

33. Sebastiani AM, Gabardo G, Machado JS, Todero RB, Scariot R, Costa DJ. [Epidemiological profile of patients undergoing removal of third molars at the Federal University of Parana]. Rev Cir Traumatol Buco-maxilo-fac. 2011 Jul.Set;11(3):93-101

34. Slade GD. Derivation and validation of a short-form oral health impact profile. Community Dent Oral Epidemiol. 1997 Aug;25(4):284-90. https://doi.org/10.1111/j.1600-0528.1997.tb00941.x

35. Stening K, Eriksson O, Wahren L, Berg G, Hammar M, Blomqvist A. Pain sensations to the cold pressor test in normally menstruating women: comparison with men and relation to menstrual phase and serum sex steroid levels. Am J Physiol Regul Integr Comp Physiol. 2007 Oct;293(4):R1711-6. https://doi.org/10.1152/ajpregu.00127.2007

36. Trevilatto PC, Line SR. Use of buccal epithelial cells for PCR amplification of large DNA fragments. J Forensic Odontostomatol. 2000 Jun;18(1):6-9.

37. Wijk A, Kieffer JM, Lindeboom JH. Effect of third molar surgery on oral health-related quality of life in the first postoperative week using Dutch version of Oral Health Impact Profile-14. J Oral Maxillofac Surg. 2009 May;67(5):1026-31. https://doi.org/10.1016/i.joms.2008.12.041

38. Winter GB. Impacted mandibular third molars. Saint Louis: American Medical Book Co; 1926.

39. Zhang X, Wang B, Qiao SC, Gu YX, Shi JY, Lai HC. A study on the prevalence of dental anxiety, pain perception, and their interrelationship in Chinese patients with oral implant surgery. Clin Implant Dent Relat Res. 2019 Jun;21(3):428-35. https://doi.org/10.1111/cid.12779 